$\frac{320}{12.27} \cdot 41$

\title{
UCRL 9663
}

\section{UNIVERSITY OF CALIFORNIA}

Ernest O. Lawrence Radiation

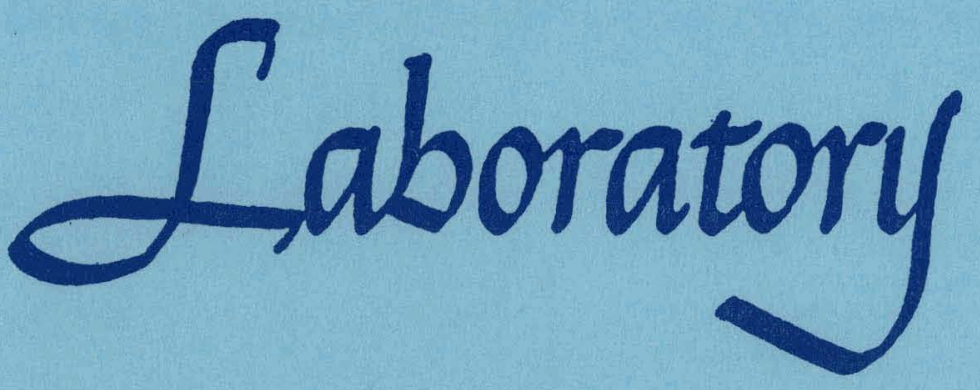

DISMANTLING ENCLOSURE FOR EXTERNAL CYCLOTRON TARGETS

BERKELEY, CALIFORNIA 


\section{DISCLAIMER}

This report was prepared as an account of work sponsored by an agency of the United States Government. Neither the United States Government nor any agency Thereof, nor any of their employees, makes any warranty, express or implied, or assumes any legal liability or responsibility for the accuracy, completeness, or usefulness of any information, apparatus, product, or process disclosed, or represents that its use would not infringe privately owned rights. Reference herein to any specific commercial product, process, or service by trade name, trademark, manufacturer, or otherwise does not necessarily constitute or imply its endorsement, recommendation, or favoring by the United States Government or any agency thereof. The views and opinions of authors expressed herein do not necessarily state or reflect those of the United States Government or any agency thereof. 


\section{DISCLAIMER}

Portions of this document may be illegible in electronic image products. Images are produced from the best available original document. 
UCRL- 9663

UC-28 Particle Accelerators and High-Voltage Machines TID-4500 (16th Ed.)

\author{
UNIVERSITY OF CALIFORNIA \\ Lawrence Radiation Laboratory \\ Berkeley, California \\ Contract. No. W-7405-eng-48
}

\title{
DISMANTLING ENCLOSURE FOR EXTERNAL CYCLOTRON T ARGETS AT THE 60-INCH CYCLOT RON
}

George L. Wigle, Neil C. Spencer, and Edward S. Fleischer

September 6, 1961 


\title{
DISMANTLING ENCLOSURE FOR EXTERNAL CYCLOTRON TARGETS AT THE 60-INCH CYCLOT RON
}

\author{
George L. Wigle, Neil C. Spencer, and Edward S. Fleischer \\ Lawrence Radiation Laboratory \\ University of California \\ Berkeley, California \\ September 6, 1961
}

\begin{abstract}
A shielded enclosure has been developed for dismantling bombarded 60-inch cyclotron "Microtargets". Consisting of a Berkeley box within a lead enclosure, it permits the operator to safely remove the target holder from the complete target. block as sembly, visually inspect the target itself, check it and the block for external alpha contamination, and remove both the target and the block assembly through a bagout sealing system. In case of contamination, the internal enclosure may be sealed off and removed as a unit, to be replaced with identical stand-by equipment.
\end{abstract}




\title{
DISMANTLING ENCLOSURE FOR EXTERNAL CYCLOTRON T ARGETS AT THE 60-INCH CYCLOT RON
}

\author{
George L. Nigle, Neil C. Spencer, and Edward S. Fleischer \\ Lawrence Radiation Laboratory \\ University of California \\ Berkeley, California
}

\section{INT RODU CTION}

Early demands for a chemistry target for the 60-inch cyclotron led to the design by Corum and Burton of the external microtarget assembly. This target assembly has proved over the years admirably suited to isotope production. Because the relatively intense beam of the cyclotron imposed special thermal problems, however, the design of the target assembly is somewhat more complex than for most targets for other accelerators. This complexity, coupled with high induced activity of certain portions of the assembly, imposed rather stringent requirements on the handling procedure. An earlier model dismantling enclosure, though adequate in terms of shielding, left something to be desired in terms of ease of handling. The second model, herein described, has been an attempt to incorporate the basic handling procedure for the 60-inch cyclotron operations with remotely operated equipment.

\section{THE TARGET ASSEMBLY}

The fully assembled target unit (Fig. 1) as designed by Corum and Burton is a sandwiched block approximately 4 in. thick. It consists of a graphite precollimator, A, mounted on a water-cooled aluminum alloy section, B; a middle electrically insulating section, C, containing a collimator , D; and two isolation (or degrader) foils, E; and the rear aluminum alloy section, $G$, which contains the target holder itself, $H$. The volume between the two isolation foils is cooled either with flowing air or, as occasion demands, with helium. The rear chamber, which contains the target holder, may be cooled either with static or flowing helium. The target holder is water-cooled, whereas the up-beam side of the target itself is helium cooled. During bombardment two water lines are attached to the front precollimator section, and five coolant lines in a single turret-type connector are attached to the rear block manifold. After bombardment the front two water lines are de. tached, and the block and remaining coolant lines are removed from the cyclotron and carried to the shield for disassembly. 


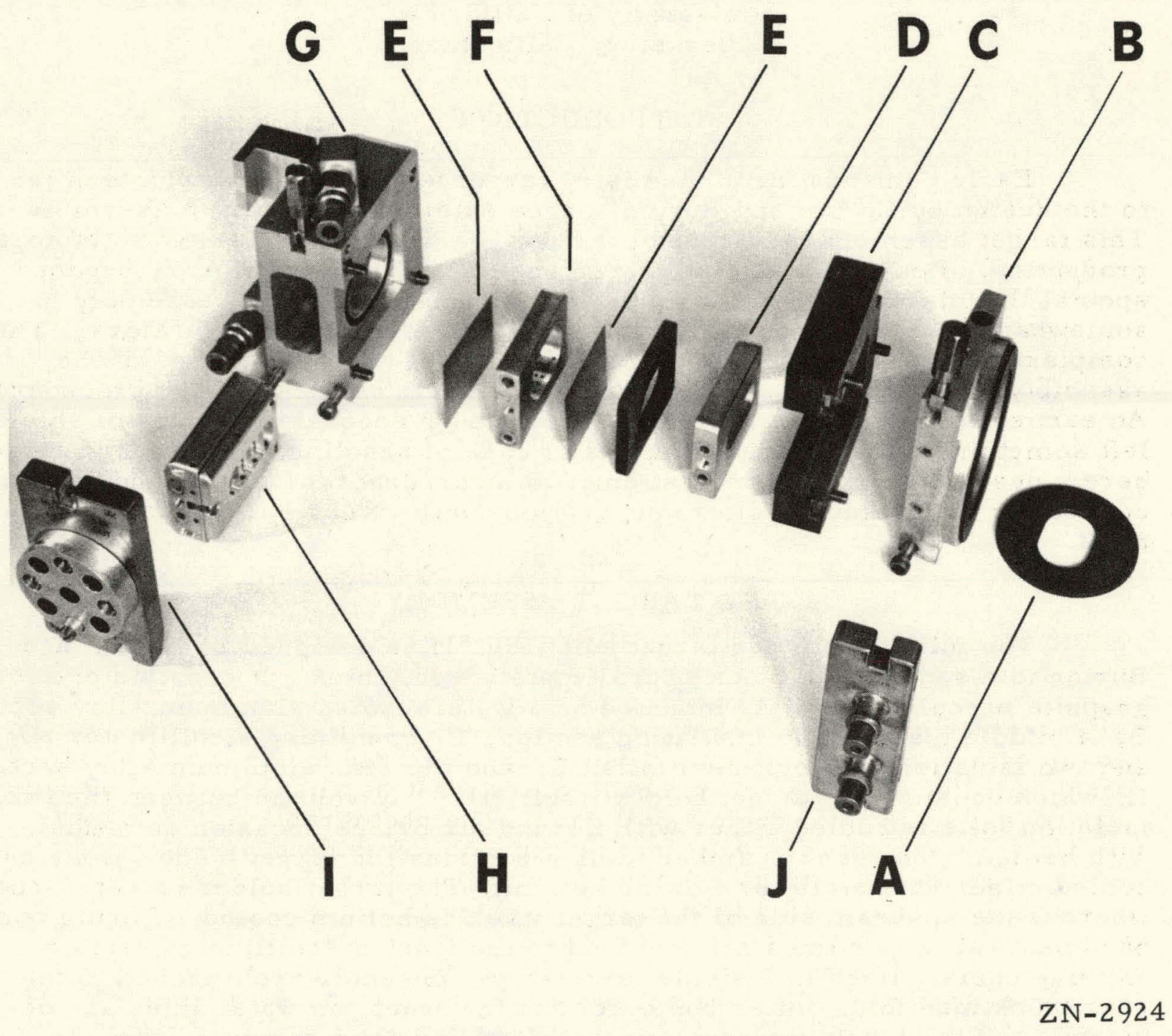

Fig. 1. Target block assembly, exploded view. 


\section{DISMANTLING ENCLOSURE}

The enclosure (Fig. 2) consists of a special Berkeley box enclosed on the sides with 2-in. -thick lead and on the front with 2 -in. lead, and fitted with a lead glass window which provides protection equivalent to 2 in. of lead. The rear of the lead cave is open and is placed against a concrete wall. Two sets of opposing channels (mounted respectively on the bottom of the box and on the steel base within the lead enclosure) and a latch precisely position the Berkeley box within the shield. To aid in easily moving the box in or out of the shield, two rows of ball bearings are also mounted on the enclosure platform. Access to the interior of the box is through two doors on the left end. A double-acting, two-positioned latch (shown at the upper left side of the shield in Fig. 2), when fully depressed by the operator, permits the outer lead door and the inner wooden box door to open all the way. Both doors are gravity-actuated. The lead door, hung by Thompson sleeve bearings on an inclined shaft, rides smoothly when released from the latch. The inclination of the shaft, hence the door's speed, is adjustable. The wood door, on the other hand, is opened with a dropping lead weight which gives a more uniform and dependable motion than a spring operation.

\section{THE DISMANTLING OPERATION}

Inside the box, directly in line with the left doors, is a turntable (Fig. 3). The target block assemlby is passed through the doors and set in a massive brass fixture atop the curntable. The fixture is designed both to provide additional shielding for the "hot "front precollimator and to hold the block firmly for subsequent manipulation. It rotates on a flat Teflon gasket as a bearing. Between the turntable shaft and the base is an O-ring moisture seal to prevent decontaminating fluids from spreading into the inaccessible gear section below. The orientation of the turntable is critical. As mentioned, it is directly in line with the left door; further, when the target block assembly rests in the brass fixture, the center of the five-way manifold must line up with a special tool extending through a Castle mount in the shield front; thirdly, a fitting on one of the gears must be aligned with a second shaft extending through the shield front. (The photograph for Fig. 3 was made before a precise location for the turntable was determined, hence the temporary taped strips as shown.) With the doors closed, a quarter turn on the outside handle then properly orients the block with respect to the second tool. Both this tool and the turntable shaft are, of course, isolated from the exterior with plastic socks. The dismantling tool has the dual function of loosening all three screws on the target manifold from a single pivot point in the shield, and of grasping the target holder and removing it from the block. The tool is a coaxially mounted Allen wrench and male screw in a spring-loaded universal joint.

With the three Allen head cap screws on the target block loosened, the block manifold is swung aside, exposing the target holder in its chamber With the threaded portion of the tool, the target holder is withdrawn and held up to the window for visual inspection. The lead door is manually rolled 


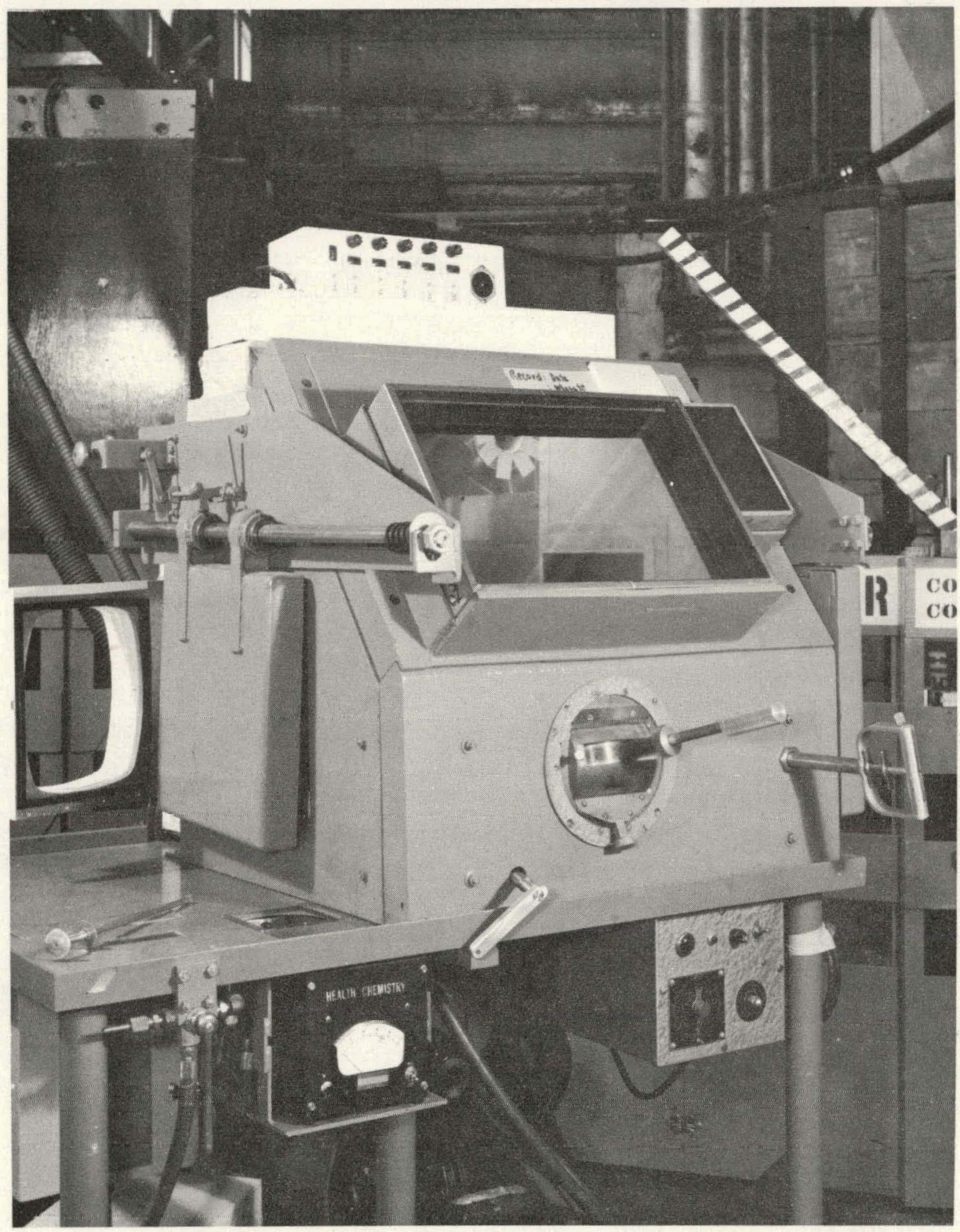

ZN-2923

Fig. 2. Disassembly cave, front view. 


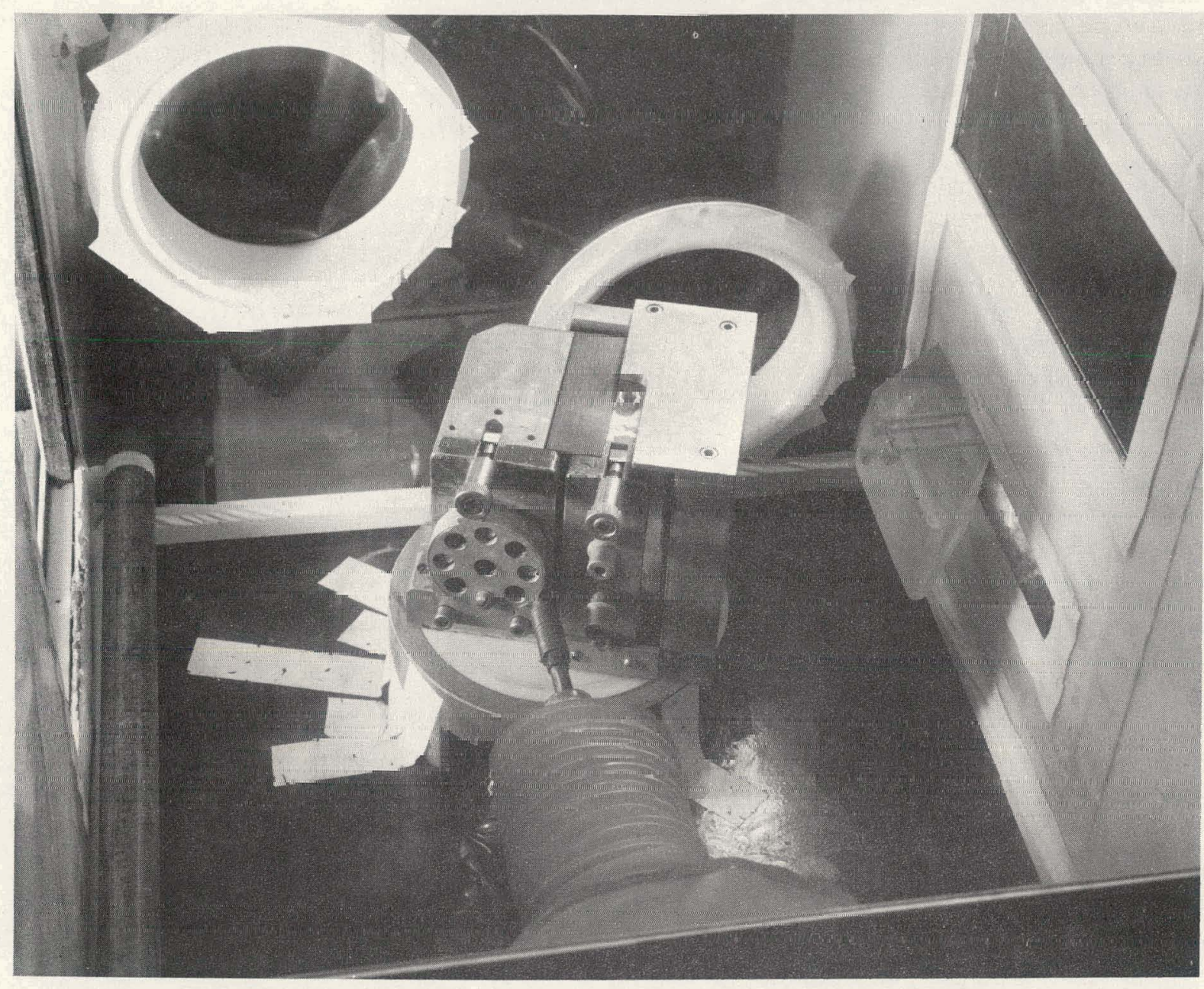

ZN-2926

Fig. 3. Disassembly cave, interior. 
to a 2-in. opening, while a slight push on the latch opens the inner box door a corresponding distance. This limited opening to the box, while retaining a flow of air into the box, allows the monitor with airplane tongs to acquire a swipe sample from the interior of the target chamber and the target face. The swipe is brought out near the surface of an alpha probe which is mounted beneath the floor of the dolly and checked for activity level. The probe is beta-, gamma-, and neutron-insensitive--a necessary quality for operation in the background normal to accelerator environments.

If visual and alpha inspection indicate it is safe, the target holder is guided out through a slot in the opposite side of the box, between the open jaws of an electric bag sealer, and into a plastic bag (Fig. 4). Mounted directly above the bag, but still within the confines of the cave, is a gamma probe to indicate levels of the holder itself. The bag is sealed, cut, and dropped in one operation into a shielded carrying case waiting below, ready for transportation to the researcher.

Mounted on the left side of the box, next to its sliding doors, is an oversized hinged port to which a large plastic bag may be attached (Fig. 2). If the target has been found to be ruptured, and the box therefore contaminated, the lead door is independently opened its full width and the port swung shut. A pressure latch on the box and gasketing around the port assure an airtight seal. The box door is now opened full width. A special tool working in the bag, without perforating it, grasps the target block and withdraws it from the shield. With the block thus enclosed in plastic, the bag is heat-welded, cut, and removed. In order to insure protection to the operator during this sealing operation, a lead slab may be raised in front of the block by means of a compressed air cylinder (Fig. 2). The integrity of the box's isolation has been maintained throughout the entire procedure. The enclosure can then be sealed off in the standard manner, the front through-shield tools removed, and the box rolled out the rear of the shield. A duplicate stand-by box is inserted, and the cave is again ready for operation. 


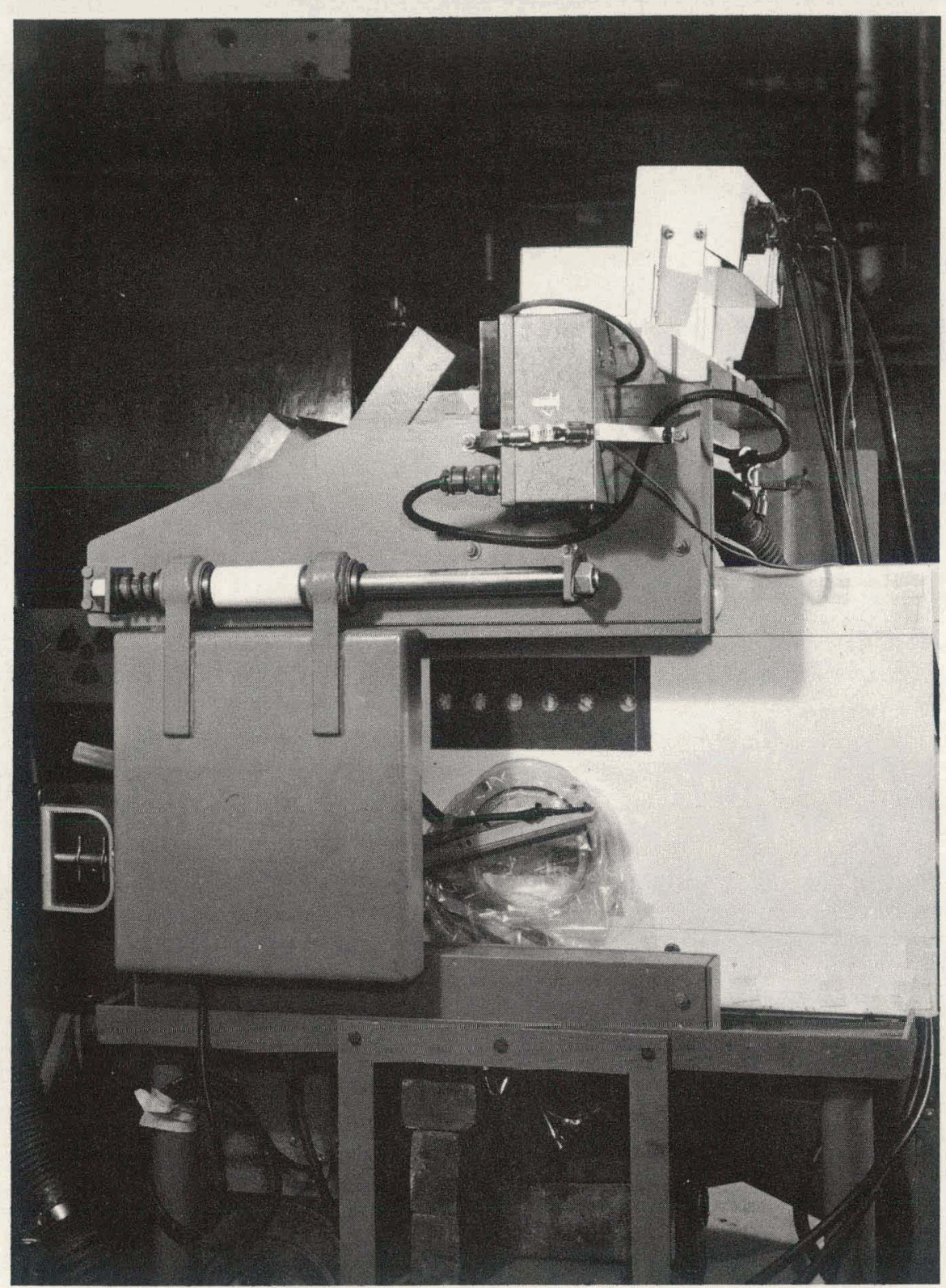

$\mathrm{ZN}-2925$

Fig. 4. Disassembly cave, right side. 


\section{REFERENCES}

1. Charles Corum, 60-Inch Cyclotron Development, in Physics Division Quarterly Report, UCRL-2920, March 1955.

2. H. P. Cantelow, L. E. Miles, and B. D. Abram, A Simple Rapid Welder for Plastic Bags and Sleeves, UCRL-9209, Aug. 1960. 
This report was prepared as an account of Government sponsored work. Neither the United States, nor the Commission, nor any person acting on behalf of the Commission:

A. Makes any warranty or representation, expressed or implied, with respect to the accuracy, completeness, or usefulness of the information contained in this report, or that the use of any information, apparatus, method, or process disclosed in this report may not infringe privately owned rights; or

B. Assumes any liabilities with respect to the use of, or for damages resulting from the use of any information, apparatus, method, or process disclosed in this report.

As used in the above, "person acting on behalf of the Commission" includes any employee or contractor of the Commission, or employee of such contractor, to the extent that such employee or contractor of the Commission, or employee of such contractor prepares, disseminates, or provides access to, any information pursuant to his employment or contract with the Commission, or his employment with such contractor. 